\title{
Applying Problem Based Learning to Improve Student Engagement in an Engineering Economics Course
}

\author{
Joseph A. Donndelinger \\ Baylor University
}

\begin{abstract}
Maintaining high levels of student engagement and interest is a widespread challenge in teaching Engineering Economics courses. To address this challenge at Baylor's School of Engineering and Computer Science, a series of problem-based homework assignments focused on personal investing and tax return preparation have been developed and integrated into the Global Business Economics and Communication course. This transition in course structure has resulted in significant improvements in student engagement as measured by class attendance, homework completion rates, and course evaluation statistics. This transition also increased polarization of students' academic performance which may be addressed through further development of the problem-based learning course content.
\end{abstract}

Keywords: engineering economics, entrepreneurial mindset, active learning, problem-based learning

\section{INTRODUCTION}

Instilling an Entrepreneurial Mindset in undergraduate students is a foundational goal of the Engineering programs at Baylor University as reflected in the mission statement of the Mechanical Engineering Department (2018): "Our graduates...will be empowered by innovative problem-solving creativity and an entrepreneurial mindset." A broad-based effort is underway to instill an Entrepreneurial Mindset within the Engineering programs at Baylor University (Van Treuren et al., 2016; Kelley, 2017). In this effort, the Entrepreneurial Mindset is defined according to the Three C Framework developed by the Kern Entrepreneurial Engineering Network (2018):

- Curiosity: Students will demonstrate constant curiosity about our changing world and explore a contrarian view of accepted solutions

- Connections: Students will integrate information from many sources to gain insight and assess and manage risk

- Creating Value: Students will identify unexpected opportunities to create extraordinary value and persist through and learn from failure

Wilck et al. (2014) and Kelley (2017) have shown that courses in Engineering Economics effectively support the development of an Entrepreneurial Mindset. A course in Engineering Economics is required for all students in Baylor's undergraduate engineering programs, complementing the goal of instilling the Entrepreneurial Mindset. Most students satisfy the Engineering Economics requirement with a conventional course offered by the Economics Department in Baylor's Hankamer School of Business. However, engineering students may also satisfy this requirement by taking Global Business Economics and Communication (GBEC), an elective course offered by Baylor's School of Engineering and Computer 
Science. This course is intended for engineering students with deeper interests in exploring value creation opportunities from both technical and business perspectives.

Maintaining high levels of student engagement and interest is a widespread challenge in teaching Engineering Economics (Zoghi, 2015). The subject matter differs substantially from typical engineering course content and students often struggle to recognize its relevance to either their personal or professional goals. Alternative pedagogical approaches such as problem-based learning (Prince, 2004; Smith et al., 2005) have proven effective for increasing student engagement in addition to improving academic achievement and long-term comprehension. More specifically for the subject of Engineering Economics, emphasizing the relevance of the course material to topics in personal finance (e.g. home ownership, life insurance, retirement planning) has been shown to improve students' motivation to learn and comprehension of course content (Eschenbach and Lewis, 2015).

This paper covers the integration of problem-based homework assignments to complement existing team-based class projects in GBEC. The goal for this transition in course structure was increasing student engagement as measured by class attendance, homework assignment completion rates, and course evaluation responses. The historical context of the course content and student engagement are presented in the next section, followed by a discussion of the development and implementation of the problem-based course content. The paper concludes with comparison of year-over-year student engagement statistics along with a discussion of further opportunities for improvement of the problem-based learning materials.

\section{HISTORICAL CONTEXT AND MOTIVATION}

GBEC was originally developed in 2009 in support of the larger initiative to offer a certificate program in Technology Entrepreneurship. This is an elective course that may be taken as an alternative to the conventional Engineering Economics course that is required for all students in Baylor's undergraduate engineering programs. As such, the course was patterned after a conventional engineering economics course, supplemented with content on persuasive communication and a team-based class project. The supplemental content proved helpful for transitioning students from traditional engineering coursework to the successive courses in the Technology Entrepreneurship certificate program, which are predominantly project-based and cross-disciplinary in nature. Nonetheless, maintaining strong student engagement in GBEC through delivery of the Engineering Economics content proved challenging. In this study, student engagement is gauged using the following metrics:

- Attendance Rates: Percentage of students absent or late for more than $10 \%$ of class periods or more than $20 \%$ of class periods

- Homework Completion Rates: Percentage of students failing to turn in one homework assignment or more than one homework assignment

- Course Evaluation Statistics: Means and standard deviations of students' responses on a 6point scale (1=Strongly Disagree, 6=Strongly Agree) to Question 12 ("The instructor stimulated my interest in this subject") and Question 13 ("The instructor stimulated my thinking") on the course evaluation.

Student engagement statistics for the Fall 2016 GBEC session are shown in Table 1. The student engagement statistics from the Fall 2016 session left considerable room for improvement. The approach for improving student engagement is presented in the next section.

\section{APPROACH}

There were a total of six homework assignments in the Fall 2016 GBEC session. The first was a problem-based session in which students developed value propositions from the perspectives of technologists, venture capitalists, and philanthropists based on a proposal for local production of Lithium Ion batteries for residential use in Haiti (Foss et al., 2014). The last was another problem-based assignment mirroring content of the team-based class project on residential implementation of renewable energy 
technology. The four intervening homework assignments were a series of exercises from Chapters 2-6 of the course textbook authored by Newnan, Lavelle, and Eschenbach (2013).

\section{TABLE 1 \\ FALL 2016 GBEC STUDENT ENGAGEMENT STATISTICS}

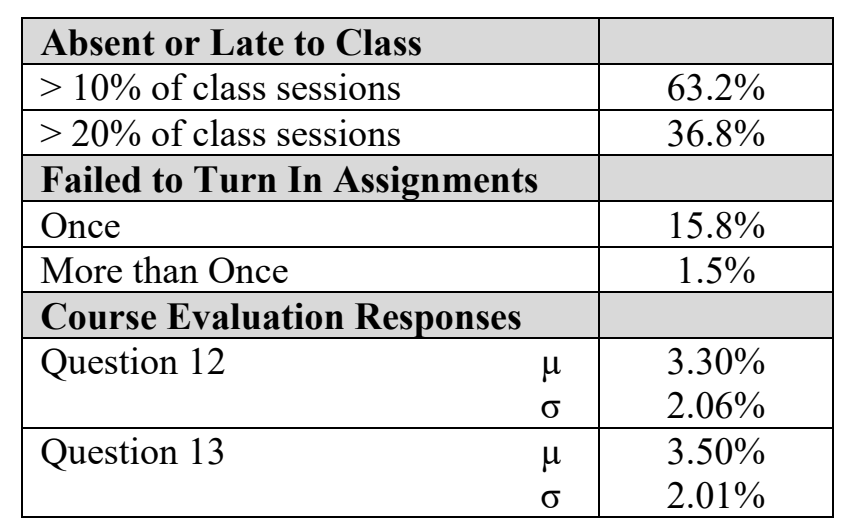

In the 2017 GBEC session, this series of homework assignments was replaced by a thematicallyconnected series of skill development assignments in which students are placed in the roles of financial consultants serving hypothetical clients in need of financial and tax planning services. In Assignment 1, each student gathered rates of return for a bank savings account, a single stock, a single issue bond, a stock mutual fund, and a bond mutual fund. The students then aggregated this information in a classroom exercise to generate an infographic for comparing the means and variances of the rates of returns of each of these classes of investment. The assignment was intended to provide context for rates of return to be used in subsequent assignments. The infographic generated by students in the classroom exercise is shown in Figure 1.

FIGURE 1

\section{RATE OF RETURN INFOGRAPHIC GENERATED IN CLASS}

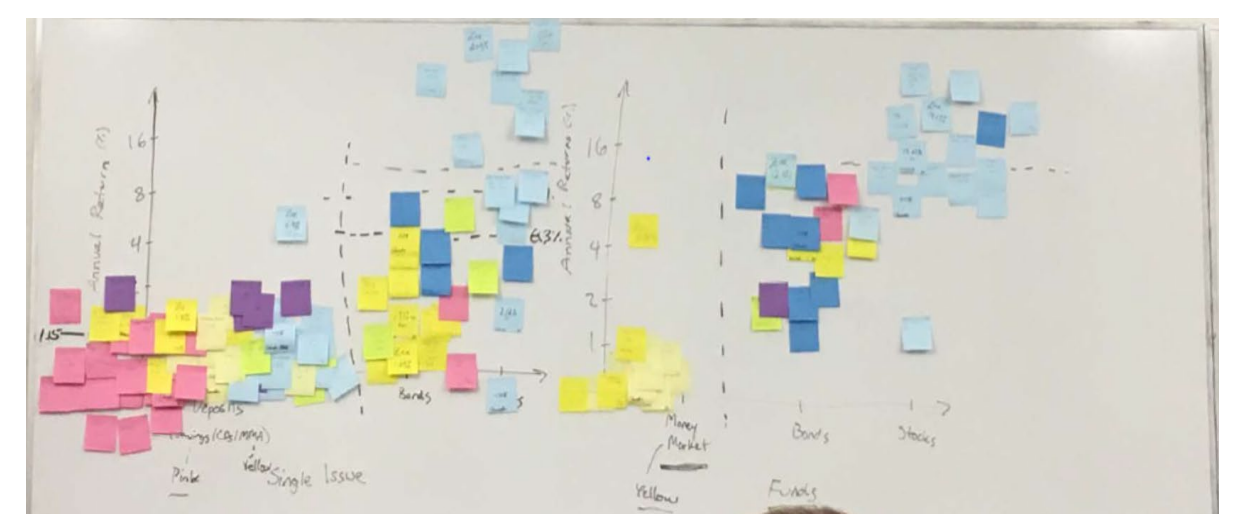

In Assignment 2, students analyzed prices and yields of zero-coupon bonds to advise hypothetical clients who were considering investing in these instruments. This assignment was intended to develop proficiency in applying Single Payment formulas. In Assignment 3, students developed retirement plans for hypothetical clients under multiple scenarios with varying investment returns and life expectancies. This assignment was intended to develop proficiency in applying Uniform Series formulas. Finally, in Assignment 4, students determined tax liabilities for both hypothetical individual and business clients to explore the impacts of deductions from income, capital gains, depreciation, and movements between tax 
brackets. The results of implementing this series of thematically-connected problem-based assignments are discussed in the next section.

\section{RESULTS AND DISCUSSION}

\section{Student Engagement}

As shown below in Table 2, there is unilateral improvement in student engagement statistics from the 2016 to the 2017 GBEC session. Student responses to Course Evaluation Question 12 ("The instructor stimulated my interest in this subject") rose by 2.1 points on a 6-point scale while responses to Question 13 ("The instructor stimulated my thinking") rose by 1.83 points on a 6-point scale. These increases are accompanied by substantial improvements in course attendance and completion of homework assignments.

TABLE 2

YEAR-OVER YEAR COMPARISON OF STUDENT ENGAGEMENT STATISTICS

\begin{tabular}{|c|c|c|c|}
\hline & \multicolumn{2}{|c|}{ Session } \\
\hline & & 2016 & 2017 \\
\hline \multicolumn{4}{|l|}{ Absent or Late to Class } \\
\hline$>10 \%$ of class sessions & & $63.2 \%$ & $38.1 \%$ \\
\hline$>20 \%$ of class sessions & & $36.8 \%$ & $0 \%$ \\
\hline \multicolumn{4}{|c|}{ Failed to Turn In Assignments } \\
\hline Once & & $15.8 \%$ & $9.5 \%$ \\
\hline More than Once & & $1.5 \%$ & $0 \%$ \\
\hline \multicolumn{4}{|c|}{ Course Evaluation Responses } \\
\hline Question 12 & $\begin{array}{l}\mu \\
\sigma\end{array}$ & $\begin{array}{l}3.30 \% \\
2.06 \%\end{array}$ & $\begin{array}{l}5.40 \\
0.91\end{array}$ \\
\hline Question 13 & $\begin{array}{l}\mu \\
\sigma\end{array}$ & $\begin{array}{l}3.50 \% \\
2.01 \%\end{array}$ & $\begin{array}{l}5.33 \\
0.98\end{array}$ \\
\hline
\end{tabular}

For interpreting the results in Table 2, the following two observations further amplify the improvements in student engagement statistics:

1. GBEC is a course offered exclusively to students in Baylor's School of Engineering and Computer Science. Students must attain Junior standing before enrolling in GBEC and are therefore predominantly enrolled in Engineering courses (typically held in the Rogers Engineering and Computer Science Building) while taking GBEC. In 2016, GBEC class sessions were also held in the Rogers Building. In 2017, however, GBEC sessions were held in Baylor's Paul L. Foster Campus for Business and Innovation. GBEC attendance statistics showed significant improvement even though students needed to commute between the Engineering and Business campuses to attend class sessions.

2. In the 2016 GBEC session, 33\% of homework assignments not turned in were the final homework assignment, whereas in the 2017 GBEC session, $100 \%$ of homework assignments not turned in were the final homework assignment. Although this has not been confirmed, the sole explanation for students failing to turn in assignments in the 2017 GBEC session may be that the assignment was due late in the semester and the students may have believed that completing the assignment would not have a material effect on their final course grade. In the 2016 session of GBEC, a majority of assignments not turned in were due early in the semester when final course grades were much farther from being determined, suggesting that failure to complete the assignment may have been due simply to students' lack of interest in the assignment. 


\section{Student Achievement}

Among the nine common exam questions in the 2016 and 2017 sessions of GBEC, there were four with statistically significant differences in student performance levels. In the 2017 session, performance on a question covering application of the Single Payment formula to a retirement planning scenario improved to $100 \%$ correct from 79\% correct in 2016. However, performance on three questions declined in the 2017 session. One of these covered the initial amount financed on an installment loan contract given a monthly payment; performance decreased to $48 \%$ correct in 2017 from $84 \%$ correct in 2016 . The other two of these questions covered Net Present Value for series of annual cash flows; performance on these questions decreased to $79 \%$ and $69 \%$ correct in 2017 from 100\% correct and 95\% correct (respectively) in 2016. For all of these cases, the explanation of differences in performance on exam questions seems to be that homework assignments in the 2017 session of GBEC focused predominantly on personal investing at the exclusion of other personal finance subjects (such as borrowing and lending) and other fundamental Engineering Economic concepts such as Net Present Value and Equivalent Uniform Annual Worth. The scope of Problem-Based Learning assignments in future GBEC sessions must be expanded to include these subjects along with the well-received personal investing content.

\section{SUMMARY}

Developing and implementing a series of thematically-connected problem-based learning assignments focused on personal investing and tax return preparation has proven effective for improving student engagement in the GBEC course. Unilateral improvements have been observed in class attendance rates, homework completion rates, and course evaluation statistics. However, care must be taken in properly scoping the problem-based learning assignments to fully encompass the fundamental concepts of Engineering Economics. These include application of Single Payment and Uniform Series formulas to both borrowing and investing as well as introduction of concepts less prevalent in personal finance such as Net Present Value. With further development, the problem-based learning content used in GBEC may be effective both for maintaining high levels of student engagement and achieving high levels of student performance.

\section{ACKNOWLEDGEMENTS}

The author gratefully acknowledges the support for this work provided by the Kern Family Foundation through the Kern Entrepreneurial Engineering Network.

\section{REFERENCES}

Baylor University. (n.d.). Department of Mechanical Engineering. School of Engineering and Computer Science. Retrieved January 21, 2018, from https://www.ecs.baylor.edu/index.php?id=960859

Eschenbach, T., \& Lewis, N. (2015). Teaching Students about the Value of Diversification - A Retirement Portfolio's Efficient Frontier. 122nd ASEE Annual Conference \& Exposition. Seattle, WA. Retrieved from https://www.asee.org/public/conferences/56/papers/13258/view

Foss, C., Leventhal, J., \& Mickelson, A. (2014). Rechargeable Lithium Ion Battery Units as Supplemental Energy in Haiti. IEEE Global Humanitarian Technology Conference (GHTC 2014). https://doi.org/10.1109/ghtc.2014.6970279

Kelley, B. (2017). Impact of Entrepreneurial Mindset Integration in a First-Semester Engineering Course. 2017 ASEE Gulf Southwest Annual Conference. Dallas, TX. Retrieved from https://peer.asee.org/33827

Kern Entrepreneurial Engineering Network. (n.d.). The Framework. Engineering Unleashed. Retrieved January 21, 2018, from https://engineeringunleashed.com/framework

Newnan, D.G., Lavelle, J.P., \& Eschenbach, T.G. (2013). Engineering Economic Analysis (12th ed.). Oxford University Press. 
Prince, M. (2004). Does Active Learning Work? A Review of the Research. Journal of Engineering Education, 93(3), 223-231. https://doi.org/10.1002/j.2168-9830.2004.tb00809.x

Smith, K.A., Sheppard, S.D., Johnson, D.W., \& Johnson, R.T. (2005). Pedagogies of Engagement: Classroom-Based Practices. Journal of Engineering Education, 94(1), 87-101. https://doi.org/10.1002/j.2168-9830.2005.tb00831.x

Van Treuren, K., Jordan, W., \& Fry, C. (2016). Instilling the Entrepreneurial Mindset in Engineering Undergraduates at Baylor University. 2016 ASEE Gulf Southwest Section Conference. Ft. Worth, TX.

Wilck, J., Lynch, P., \& Kauffmann, P. (2014). Engineering Economics as a General Education Course to Expand Quantitative and Financial Literacy. 121st ASEE Annual Conference \& Exposition.

Indianapolis, IN. Retrieved from https://www.asee.org/public/conferences/32/papers/8581/view

Zoghi, S. (2015). Engineering Economics and Its Role in The Engineering Curricula. 122nd ASEE Annual Conference \& Exposition. Seattle, WA. Retrieved from

https://www.asee.org/public/conferences/56/papers/14007/view 